Supporting Information

\title{
Multienzyme Targeted Fluorescent Probe as Biosensing Platform for Broad Detection of Pesticide Residues
}

Wu-Yingzheng Guo, ${ }^{\S}$ Yi-Xuan Fu, ${ }^{\S}$ Shi-Yu Liu, Long-Can Mei, Yao Sun, Jun Yin, Wen-Chao Yang, ${ }^{*}$ and Guang-Fu Yang*

Key Laboratory of Pesticide \& Chemical Biology of Ministry of Education, International Joint Research Center for Intelligent Biosensor Technology and Health, College of Chemistry, Central China Normal University, Wuhan 430079, P.R. China

\section{Table of contents}

1. NMR spectra for probe characterization $\cdot \mathrm{S} 2-\mathrm{S} 3$

2. Additional data S4-S11

3. References S12

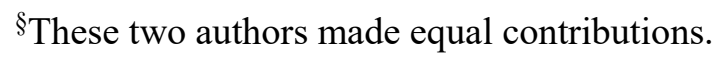

*Wen-Chao Yang, e-mail: tomyang@mail.ccnu.edu.cn; Tel: 86-27-67867706; Fax:

86-27-67867141; Guang-Fu Yang, e-mail: gfyang@mail.ccnu.edu.cn; Tel: 86-27-67867800; Fax: 86-27-67867141. 
1. NMR spectra for probe characterization

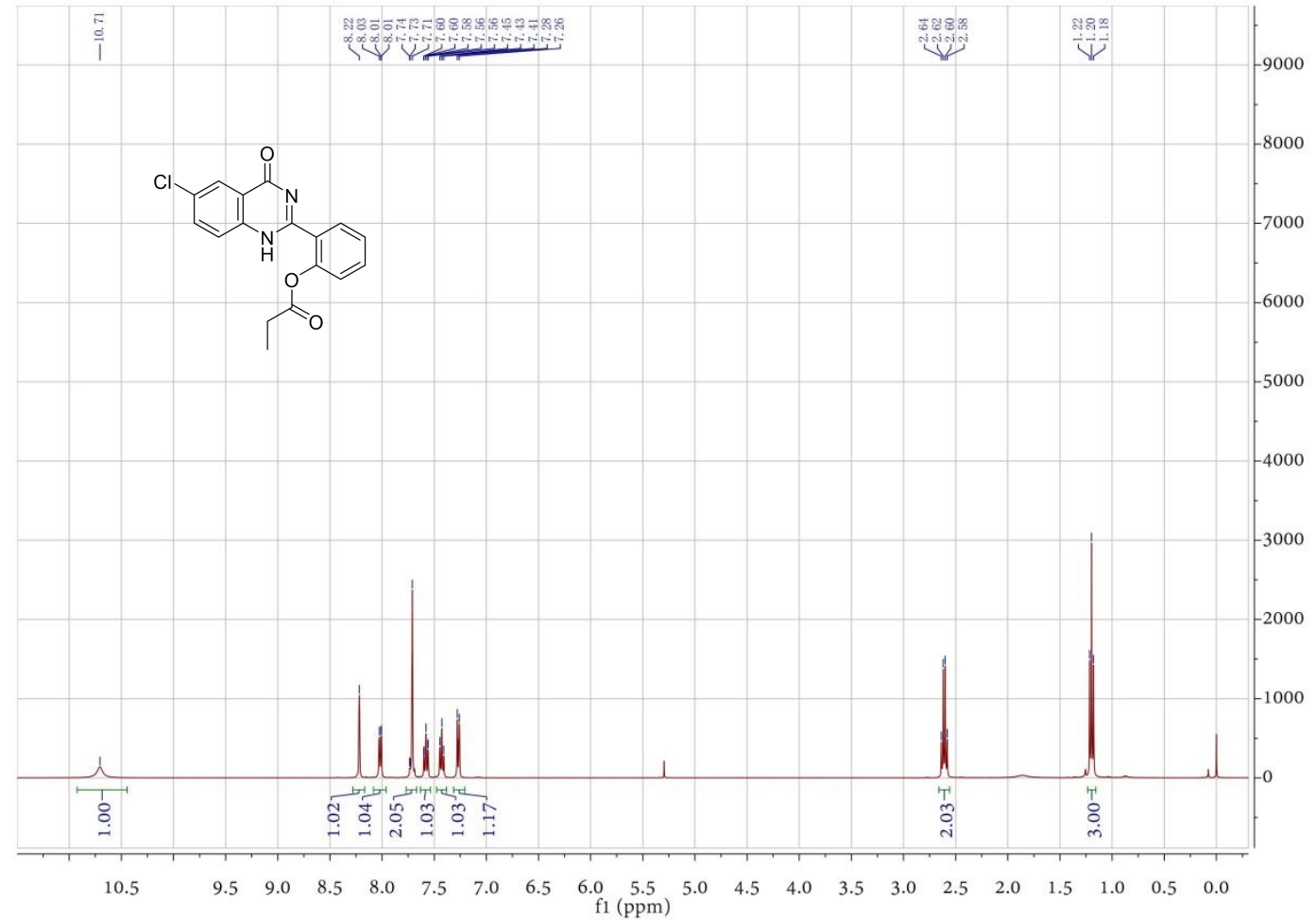

Figure $\mathbf{S 1}{ }^{1} \mathrm{H}$ NMR for $\mathbf{3 C P}$ in $\mathrm{CDCl}_{3}$. 


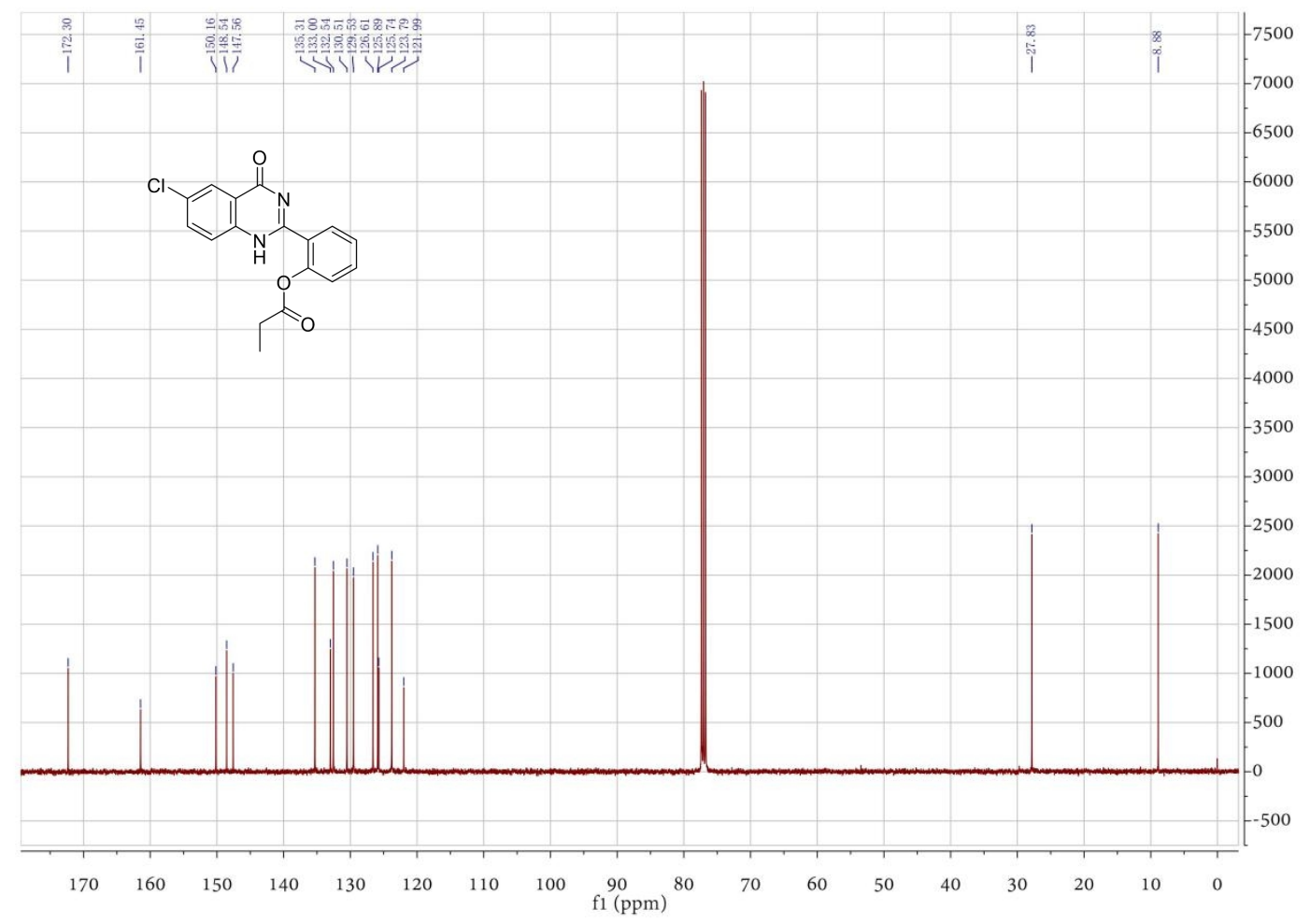

Figure $\mathbf{S 2}{ }^{13} \mathrm{C}$ NMR for $\mathbf{3 C P}$ in $\mathrm{CDCl}_{3}$. 


\section{Additional data}

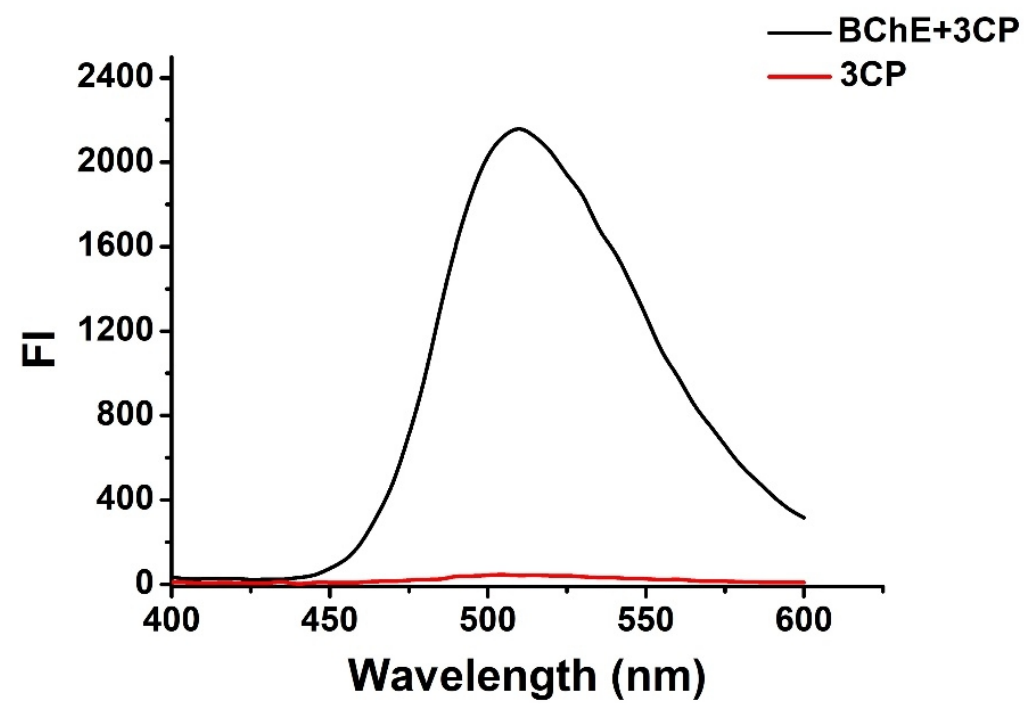

Figure S3. Fluorescent spectrum $\left(\lambda_{\mathrm{ex}}=345 \mathrm{~nm}\right)$ of $\mathbf{3 C P}(10 \mu \mathrm{M})$ with (black) and without (red) incubation with BChE $(5 \mu \mathrm{g} / \mathrm{mL})$.

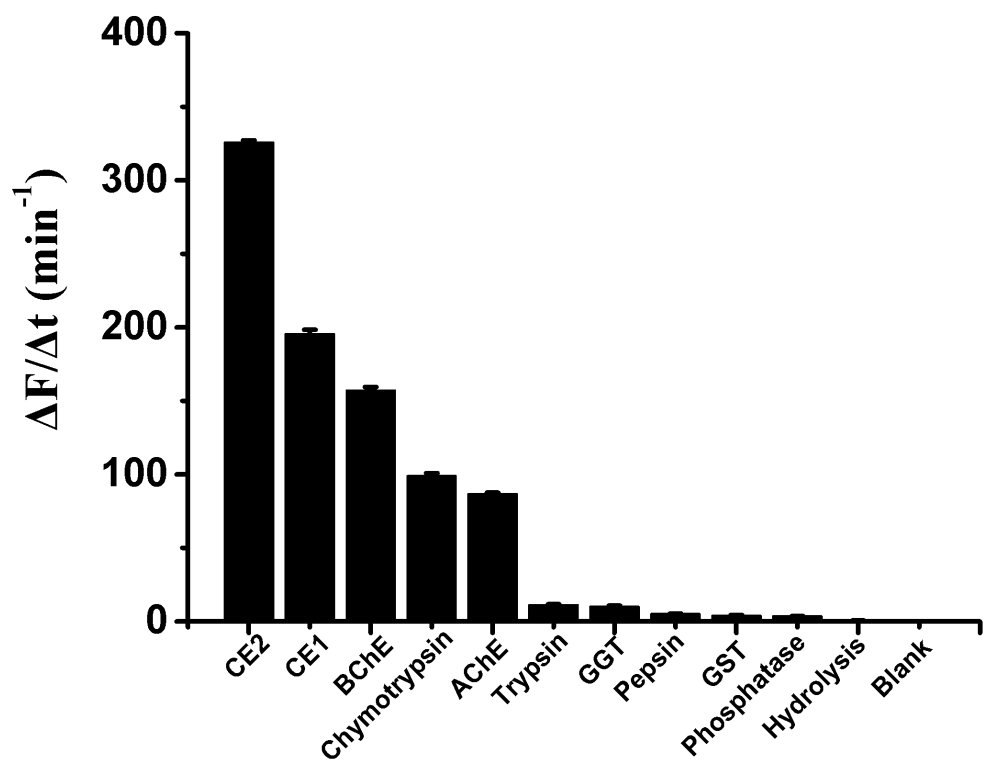

Figure S4. Fluorescence response of 3CP $(20 \mu \mathrm{M})$ toward multiple hydrolases $(10 \mu \mathrm{g} / \mathrm{mL})$ or buffer (indicated as blank). 


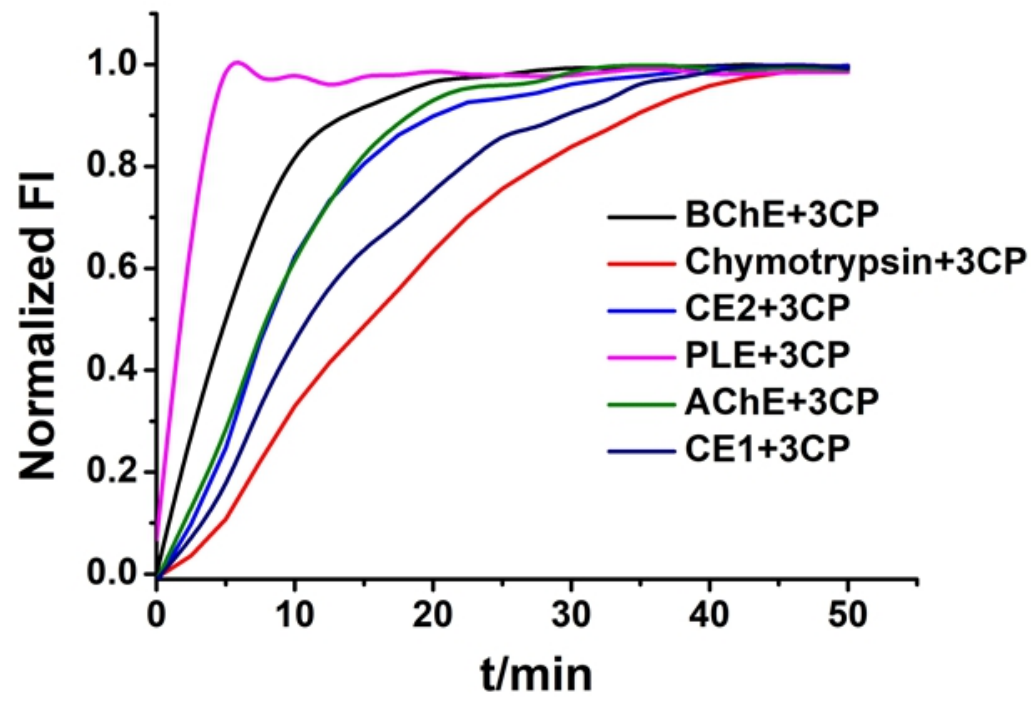

Figure S5. Time-dependent fluorescence changes of $\mathbf{3 C P}(20 \mu \mathrm{M})$ after the addition of each enzyme (10 $\mu \mathrm{g} / \mathrm{mL}$, PLE, AChE, BChE, CE1, CE2 and Chy) at the excitation wavelength of 345 $\mathrm{nm}$ and maximum emission wavelength of $510 \mathrm{~nm}$.

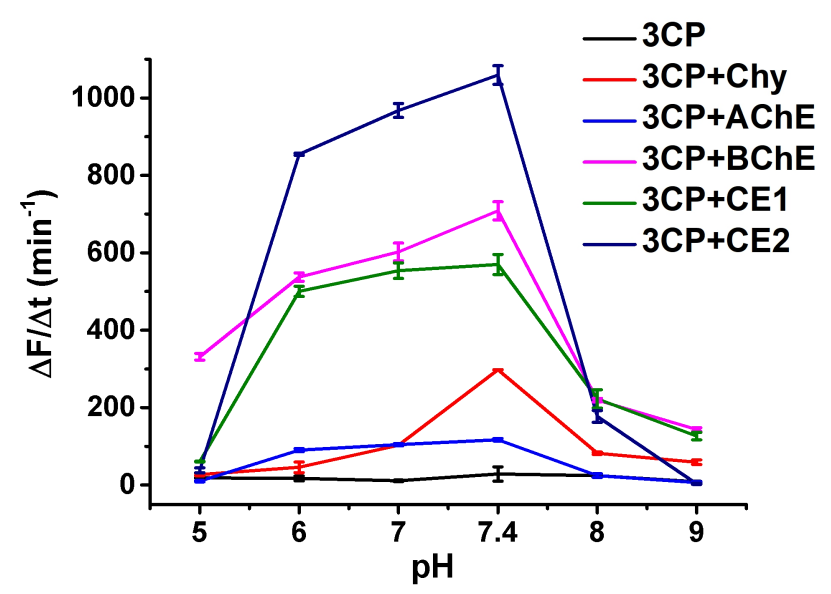

Figure S6. The pH-dependent hydrolytic rates of $\mathbf{3 C P}(10 \mu \mathrm{M})$ with the incubation of each enzyme (10 $\mu \mathrm{g} / \mathrm{mL}, \mathrm{AChE}, \mathrm{BChE}, \mathrm{CE} 1, \mathrm{CE} 2$ and Chy $)$ in aqueous solution. 

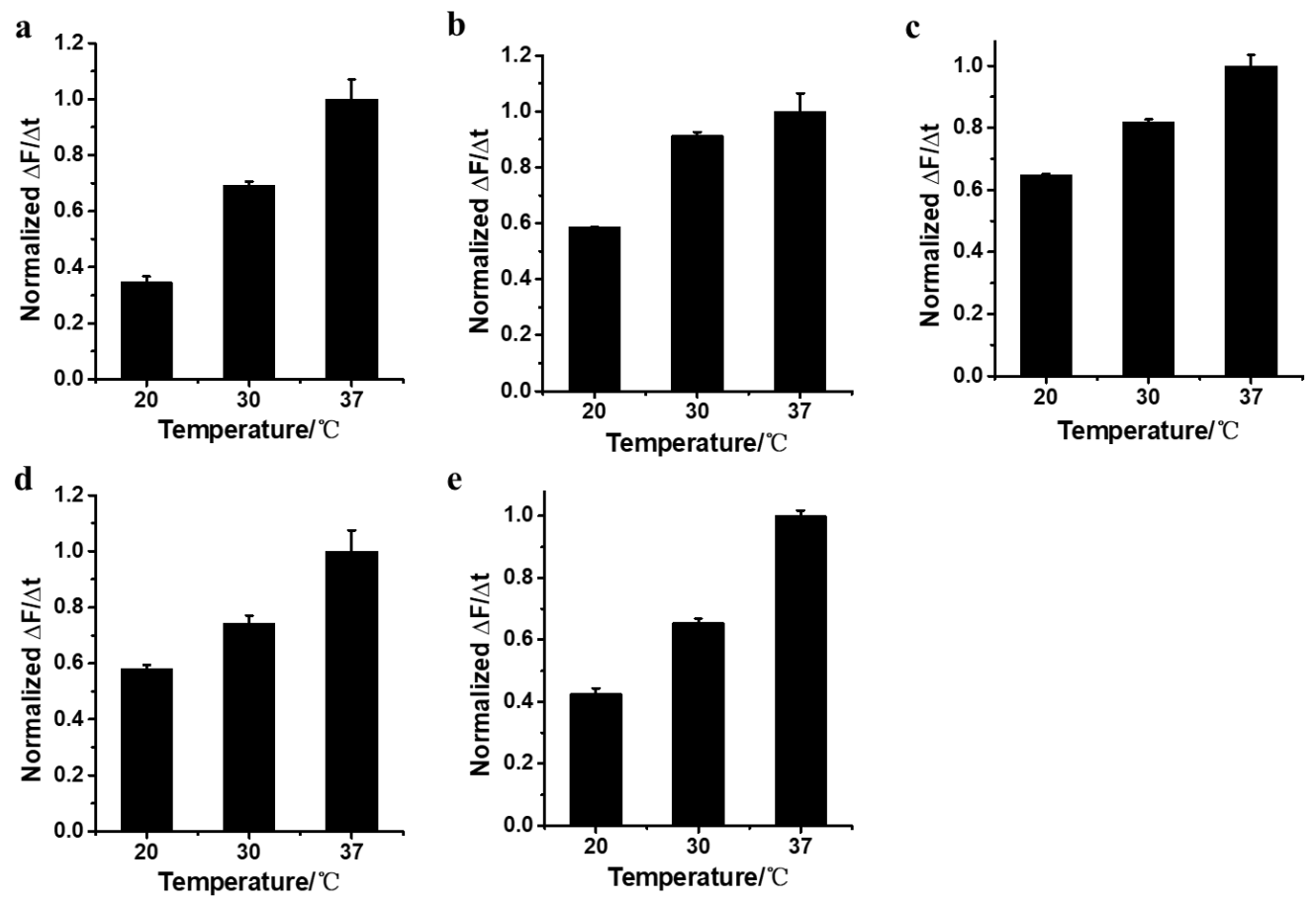

Figure S7. Normalized hydrolytic rates of $\mathbf{3 C P}(10 \mu \mathrm{M})$ with the incubation of each enzyme at different temperature. (a) $\mathrm{AChE}(10 \mu \mathrm{g} / \mathrm{mL})$; (b) BChE (10 $\mu \mathrm{g} / \mathrm{mL})$; (c) CE1 $(10 \mu \mathrm{g} / \mathrm{mL})$; (d) CE2 (10 $\mu \mathrm{g} / \mathrm{mL})$; (e) Chy $(10 \mu \mathrm{g} / \mathrm{mL})$. 

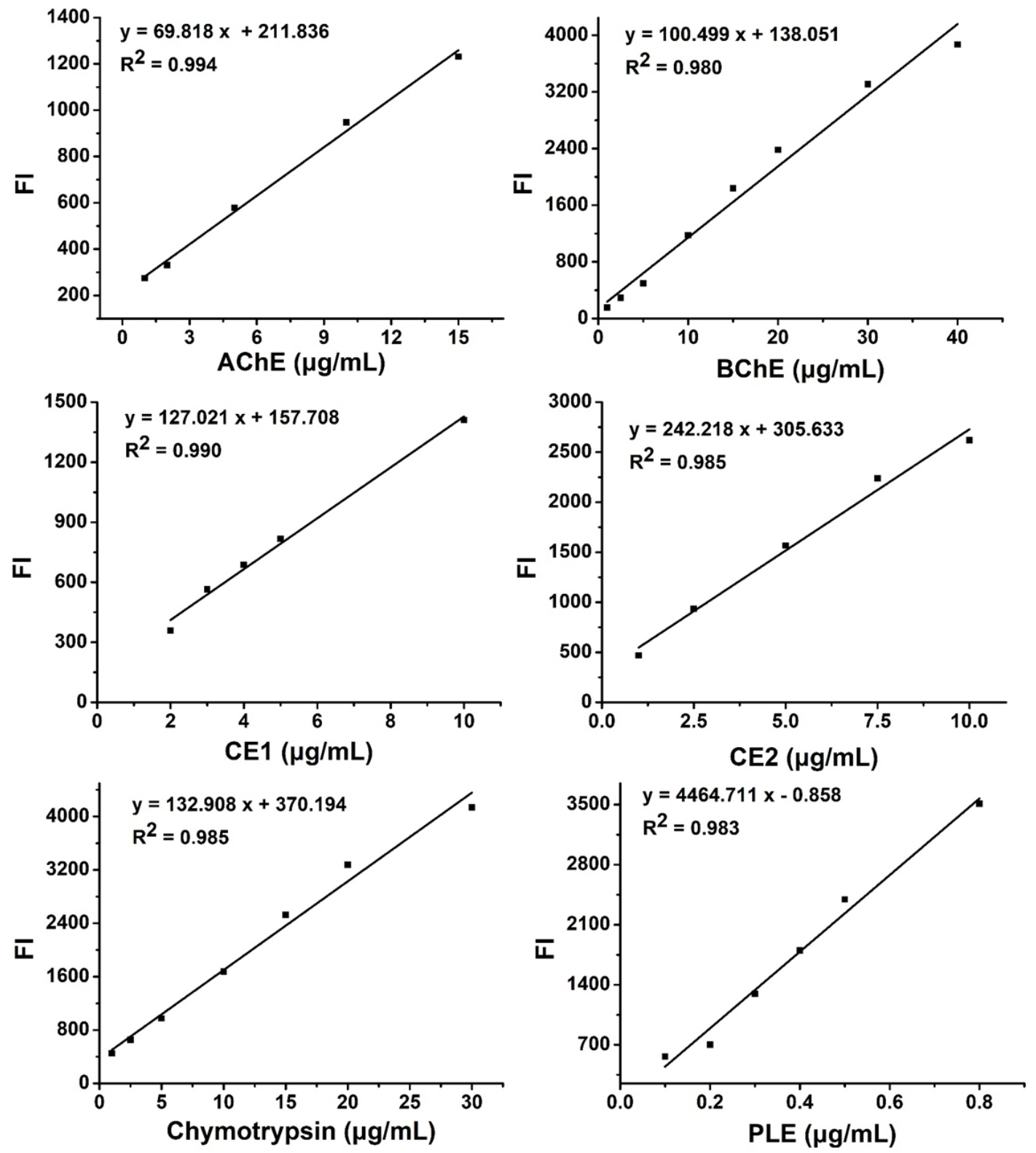

Figure S8. Dose-dependent fluorescence changes of 3CP $(10 \mu \mathrm{M})$ when incubating with each of six enzymes (PLE, AChE, BChE, CE1, CE2 and Chy) at the excitation wavelength of $345 \mathrm{~nm}$ and maximum emission wavelength of $510 \mathrm{~nm}$. 


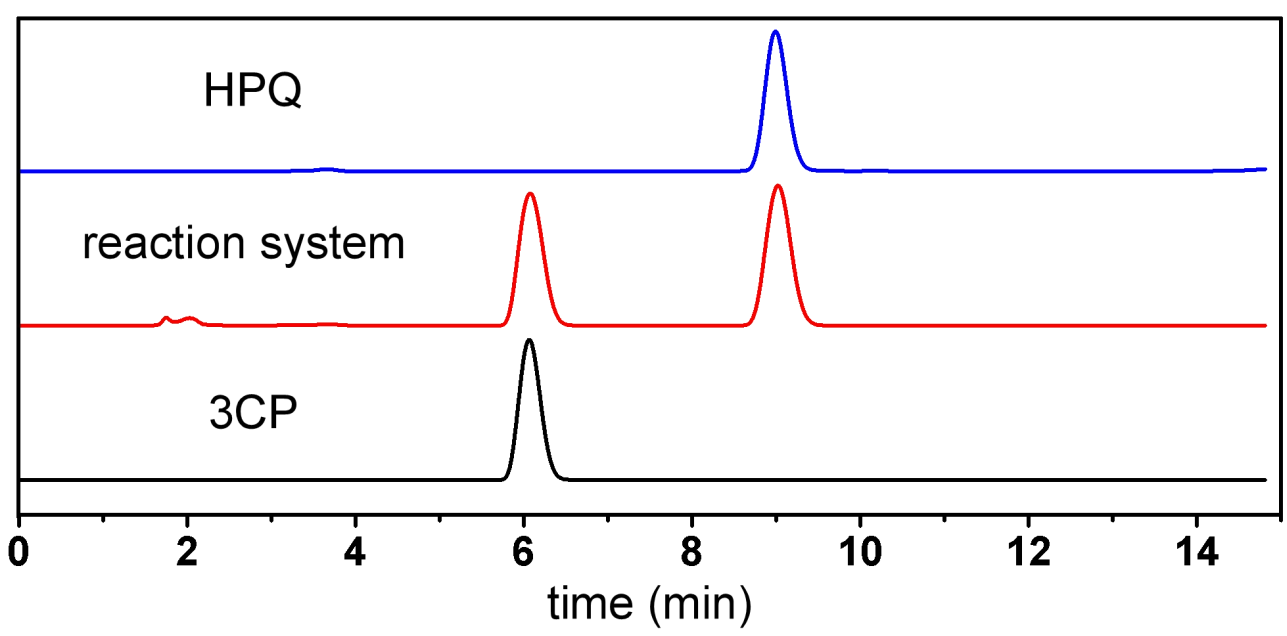

Figure S9. HPLC analysis of 3CP with (red curve) and without (black curve) the addition of human BChE. HPQ was used as control that indicated in blue line.

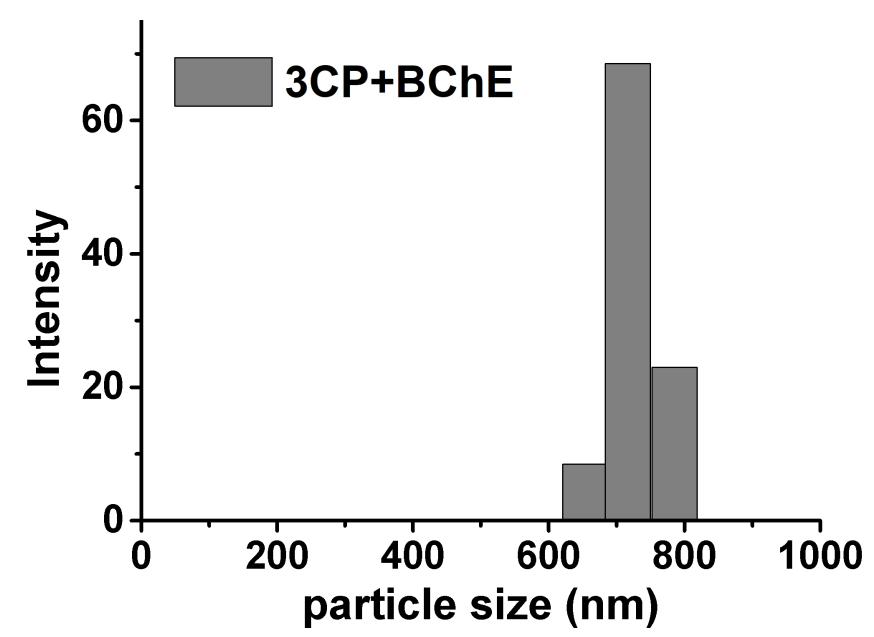

Figure S10: Particle size distributions of 3CP $(10 \mu \mathrm{M})$ after incubation with BChE $(1 \mu \mathrm{g} / \mathrm{mL})$ in PBS buffer $(\mathrm{pH}=7.4)$. 

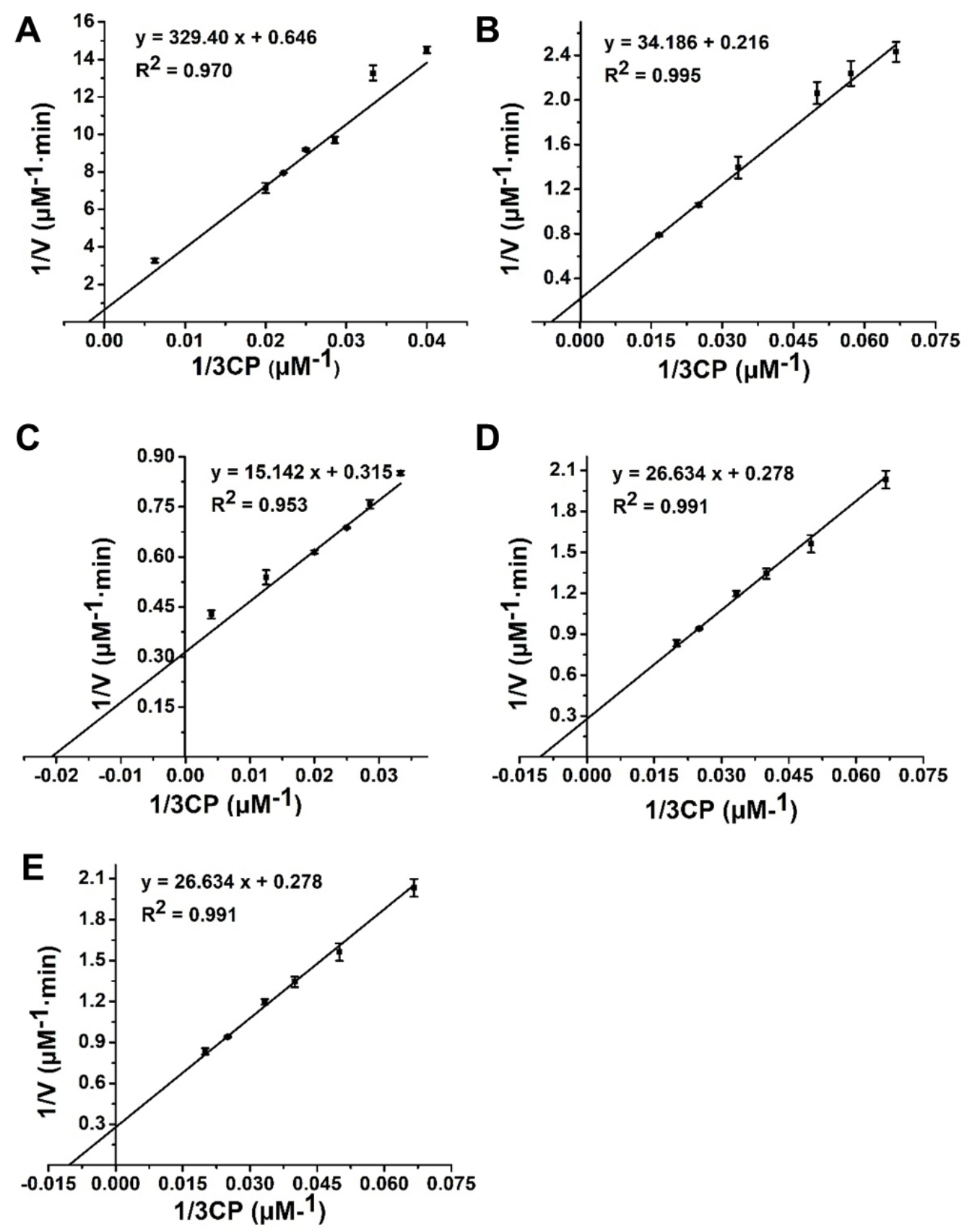

Figure S11. Michaelis-Menten curves for 3CP hydrolysis catalyzed by each of those serine hydrolases in PBS buffer (100 mM, pH 7.4). (A) AChE (10 $\mu \mathrm{g} / \mathrm{mL})$; (B) BChE (10 $\mu \mathrm{g} / \mathrm{mL})$; (C) Chy $(10 \mu \mathrm{g} / \mathrm{mL})$; (D) CE1 $(10 \mu \mathrm{g} / \mathrm{mL})$; (E) CE2 $(10 \mu \mathrm{g} / \mathrm{mL})$. 

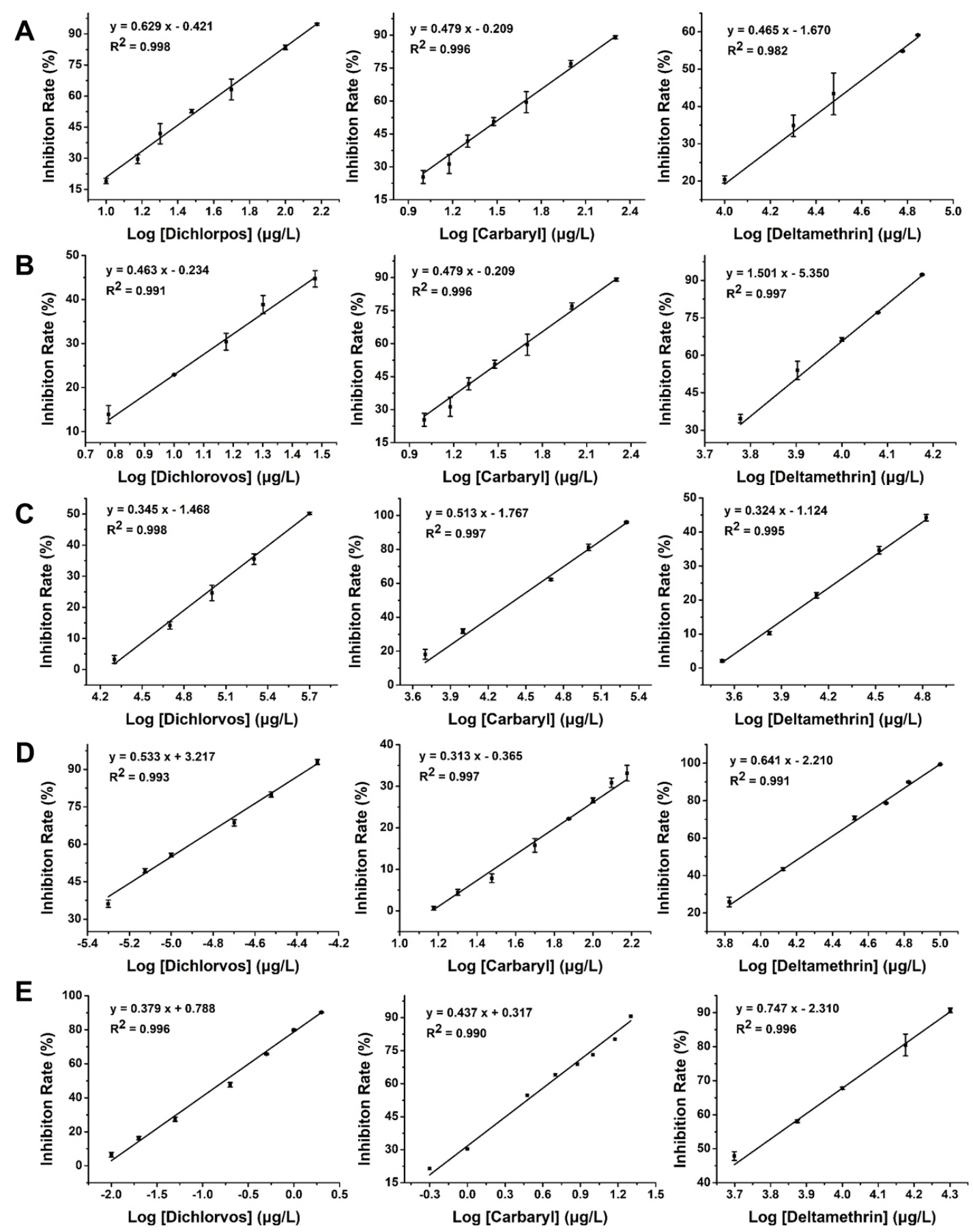

Figure S12. Standard curves of $\mathbf{3 C P}(10 \mu \mathrm{M})$-based detection against three representative pesticides (dichlorvos, carbaryl and deltamethrin) in PBS buffer $(100 \mathrm{mM}, \mathrm{pH} 7.4)$ in the presence of $\mathrm{AChE}(\mathrm{A}), \mathrm{BChE}(\mathrm{B})$, Chy (C), CE1 (D) and CE2 (E). 


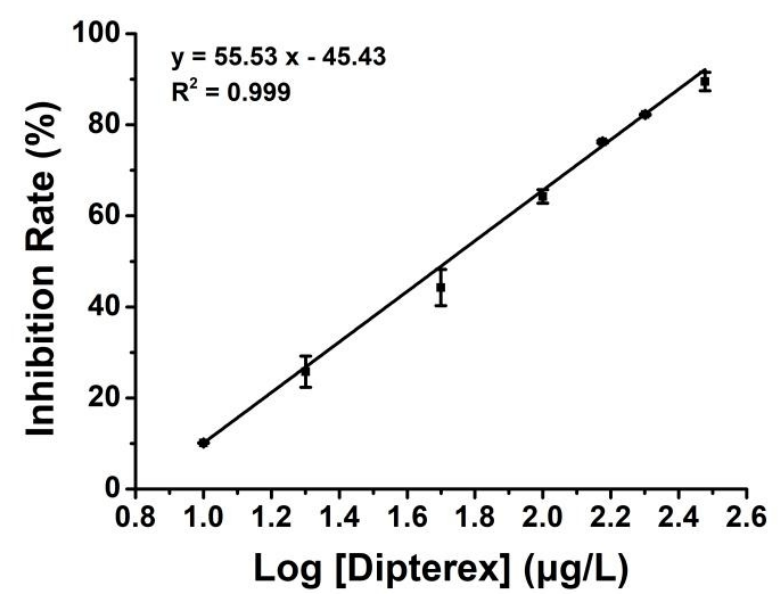

Figure S13. Inhibition kinetic curves for the dipterex detection in lettuce.

Table S1. LODs of $\mathbf{3 C P}$ for six tested serine hydrolases.

\begin{tabular}{ccccccc}
\hline & AChE & BChE & CE1 & CE2 & Chy & PLE \\
\hline $\begin{array}{c}\text { LOD } \\
(\mathrm{ng} / \mathrm{mL})\end{array}$ & 118.48 & 82.31 & 65.12 & 34.15 & 62.23 & 1.78 \\
\hline
\end{tabular}

Table S2. List of LODs for the reported probes and 3CP for pesticides detection

\begin{tabular}{ccccc}
\hline Enzyme & Pesticide & Matrix & LOD & Reference \\
\cline { 1 - 3 } CE1 & dichlorvos & Small-molecular fluorescence & $1.14 \mathrm{pg} / \mathrm{L}$ & \multirow{2}{*}{ This work } \\
\cline { 1 - 2 } CE2 & carbaryl & probe & $0.24 \mu \mathrm{g} / \mathrm{L}$ & \\
\hline AChE & dichlorvos & Platinum nanoparticles & $2.3 \mu \mathrm{g} / \mathrm{L}$ & 1 \\
AChE & dichlorvos & CdTe QDs & $0.24 \mu \mathrm{g} / \mathrm{L}$ & 2 \\
AChE & carbaryl & Gold nanoparticle & $0.1 \mu \mathrm{g} / \mathrm{L}$ & 3 \\
AChE/ChO & dichlorvos & CdTe QDs & $4.49 \mathrm{nM}$ & 4 \\
AChE & dichlorvos & Quaternized carbon dots & $1.9 \times 10^{-11} \mathrm{M}$ & 5 \\
AChE & dichlorvos & Q-CDs & $11.7 \mathrm{pM}$ & 6 \\
\hline
\end{tabular}




\section{References}

(1) Cao, J.; Wang, M.; She, Y.; El-Aty, A. M. A.; Hacımüftüoğlu, A.; Wang, J.; Yan, M.; Hong, S.; Lao, S.; Wang, Y. Rapid Colorimetric Determination of the Pesticides Carbofuran and Dichlorvos by Exploiting Their Inhibitory Effect on the Aggregation of Peroxidase-Mimicking Platinum Nanoparticles. Microchim. Acta 2019, 186 (6).

(2) Zheng, Z.; Zhou, Y.; Li, X.; Liu, S.; Tang, Z. Highly-Sensitive Organophosphorous Pesticide Biosensors Based on Nanostructured Films of Acetylcholinesterase and CdTe Quantum Dots. Biosens. Bioelectron. 2011, 26 (6), 3081-3085.

(3) Liu, D.; Chen, W.; Wei, J.; Li, X.; Wang, Z.; Jiang, X. A Highly Sensitive, Dual-Readout Assay Based on Gold Nanoparticles for Organophosphorus and Carbamate Pesticides. Anal. Chem. 2012, 84 (9), 4185-4191.

(4) Meng, X.; Wei, J.; Ren, X.; Ren, J.; Tang, F. A Simple and Sensitive Fluorescence Biosensor for Detection of Organophosphorus Pesticides Using H2O2-Sensitive Quantum Dots/Bi-Enzyme. Biosens. Bioelectron. 2013, 47, 402-407.

(5) Hou, J.; Tian, Z.; Xie, H.; Tian, Q.; Ai, S. A Fluorescence Resonance Energy Transfer Sensor Based on Quaternized Carbon Dots and Ellman's Test for Ultrasensitive Detection of Dichlorvos. Sensors Actuators, B Chem. 2016, 232, 477-483.

(6) Hu, T.; Xu, J.; Ye, Y.; Han, Y.; Li, X.; Wang, Z.; Sun, D.; Zhou, Y.; Ni, Z. Visual Detection of Mixed Organophosphorous Pesticide Using QD-AChE Aerogel Based Microfluidic Arrays Sensor. Biosens. Bioelectron. 2019, 136, 112-117. 